\title{
La prensa de la transición como cómplice de Juan Carlos I: el ejemplo de la legitimidad franquista de la Monarquía
}

\author{
RICARDO ZUGASTI \\ Universidad San Jorge
}

\begin{abstract}
The cooperation of the Spanish press with Juan Carlos I: the case of the francoist legitimacy of the monarchy during the transition to democracy
\end{abstract}

\begin{abstract}
RESUMEN ABSTRACT
el presente artículo analiza la cobertura periodística otorgada por los diarios españoles a la legitimidad franquista de la Monarquía de Juan Carlos I durante la transición a la democracia. El tratamiento concedido a dicha legitimidad puede considerarse un ejemplo útil para ilustrar las especiales relaciones de complicidad que se produjeron entre la prensa y la Corona en aquel periodo histórico, con la vista puesta en la democratización del sistema político.

PALABRAS CLAVE: Historia del Periodismo; prensa; España; Monarquía; transición política.

This article examines the press coverage of francoist legitimacy of the Spanish monarchy through the content analysis of the newspaper articles written on the subject during the transition to democracy. The journalistic treatment of the only source of legitimacy for king Juan Carlos when he was crowned has been taken as an example of general media treatment, which was based on a cooperation between press and monarchy with a view to achieving democracy.

KEYWORDS: Journalism History; Press; Spain; Monarchy; political transition.
\end{abstract}

\section{INTRODUCCIÓN}

En la historiografía sobre la transición española a la democracia existe un debate acerca de los protagonismos en dicho proceso de cambio político. A grandes rasgos, una interpretación pone el acento en las estrategias y en la capacidad de las élites políticas para conducir el tránsito a la democracia. El papel principal recayó, por consiguiente, en un grupo reducido de actores políticos, fundamentalmente procedentes de los sectores reformistas del Régimen de Franco y cuya 
cabeza fue el Rey Juan Carlos I'. Por otro lado, la explicación socioeconómica concede a la sociedad española en su conjunto el papel determinante. A este respecto, la nueva sociedad «modernizada» surgida del desarrollo económico de la década de 1960 inició inevitablemente el camino hacia la democracia, aunque no fuera ésa la intención de los dirigentes franquistas que promovieron la mejora material de la calidad de vida de los españoles².

La explicación «personalista» de la transición ha recibido críticas que le achacan el haber creado unos hiperliderazgos con el fin de legitimar democráticamente a esas personalidades reformistas del franquismo, capitalizando a posteriori, una vez conocido el final feliz del proceso, la buena imagen social del éxito de la transición. Evidentemente, la principal beneficiada de esta legitimidad sería la Monarquía, supuesta pieza insustituible en el proceso de cambio político ${ }^{3}$.

Por el contrario, la teoría socioeconómica corre el riego de caer en un determinismo que niega la libertad de las personas en los procesos históricos, a la par que obvia un elemento crucial que fue consecuencia de la dictadura franquista: la existencia de una sociedad en su mayoría desmovilizada políticamente; un cuerpo social que en su faceta activa estaba dispuesto a demandar una ampliación de los derechos políticos y una mejora de la calidad de vida, pero no cambios políticos profundos que implicasen otro modelo de Estado o la transformación del sistema socioeconómico ${ }^{4}$.

Ante esta disyuntiva se hace necesario buscar puntos de engarce entre el papel de los líderes y la función de la sociedad, ya que debe considerarse que las personalidades políticas no actuaron aisladas, sino en un entorno social del que también formaban parte. Las élites políticas procedentes del franquismo, que tuvieron un papel indiscutible en la transición porque ostentaban buena parte del poder político del Estado, realizaron la reforma política en el seno de una sociedad moderna y avanzada, cada vez más dispuesta a reivindicar o a asumir un cambio en sentido democratizador, pero en gran parte desmovilizada.

En la relación entre líderes y sociedad desempeñaron un cometido crucial los medios de comunicación, con lo que, ejerciendo su intrínseca función mediadora,

1 Véanse, a título de ejemplo, PALAcio ATARD, V.: Juan Carlos / y el advenimiento de la democracia. Madrid, Real Academia de la Historia, 1988; PASQUINO, G.: «Political leadership in Southern Europe», West European Politics, núm. 13, 1990, págs. 119-130; FERnÁndeZ-MiRANDA, P. y A.: Lo que el Rey me ha pedido. Barcelona, Plaza \& Janés, 1995.

2 Veánse, como muestra, en algunos casos matizada, MaRAvall, J. M.: La política de la transición. Madrid, Taurus, 1981; JULIÁ, S.: «Sociedad y Política», en TUÑón DE LARA, M. et alii: Transición y democracia (1973-1985). Barcelona, Labor, 1992, págs. 28-186; PÉREz DíAz, V.: La primacía de la sociedad civil: el proceso de formación de la España democrática. Madrid, Alianza, 1993; MATEos, A., y Soto, A.: El final del franquismo, 1959-1975. La transformación de la sociedad española. Madrid, Historia 16-Temas de Hoy, 1997.

3 Cfr., por ejemplo, YsÀs, P.: «El estado de las autonomías: orígenes y configuración», en NAVAJAS Zubeldia, C. (ed.): Actas del III Simposio de Historia Actual. Logroño, Gobierno de La Rioja-Instituto de Estudios Riojanos, Logroño, 2002, pág. 103.

4 Cfr. Sastre García, C.: Transición y desmovilización política en España (1975-1978). Valladolid, Universidad de Valladolid, 1997, pág. 157. 
se convirtieron en otros influyentes actores políticos. Nuestras relaciones con otras personas, objetos, organizaciones y acontecimientos están en buena medida conformadas por los conocimientos que adquirimos a través de los medios, que además son canales esenciales de contacto social ${ }^{5}$. Sin embargo, la mediación no es un mero nexo de unión entre los medios de comunicación y la sociedad, sino que aquéllos interpretan y construyen la realidad al convertir los sucesos en acontecimientos informativos ${ }^{6}$. Por lo tanto, el conocimiento de los ciudadanos españoles sobre lo que estaba acaeciendo en la transición provenía fundamentalmente de los mensajes periodísticos, que tuvieron así un destacado papel en la construcción ante la sociedad de los líderes políticos de aquella etapa de la historia de España.

Este artículo estudia precisamente la representación periodística de Juan Carlos I, la personalidad política de la que más se destaca su crucial papel en la consecución de una transición pacífica. Más concretamente, se analiza la postura de la prensa diaria ante una de las principales características de la Monarquía de Don Juan Carlos: su procedencia franquista, el tener la base de su legitimidad en el mismo acontecimiento histórico que la dictadura, es decir, el alzamiento del 18 de julio y la posterior victoria en la Guerra Civil. Los objetivos de la investigación se cifran en arrojar algo de luz sobre la prensa española de la transición, un actor generalmente olvidado en los estudios sobre aquella etapa histórica, y en explicar aun parcialmente, teniendo presente la polémica historiográfica sobre la importancia del papel de los líderes, algunas pautas sobre la representación-construcción periodística de Juan Carlos I y de su Monarquía durante aquel periodo.

Para ello analizamos cualitativamente el contenido de doce diarios españoles seleccionados como fuentes, entre el nombramiento de Don Juan Carlos como sucesor de Franco a título de Rey, en julio de 1969, y la entrada en vigor de la Constitución de $1978^{7}$. Estos periódicos fueron los madrileños ABC, Ya, El Alcázar, Pueblo, El País y Diario 16; los barceloneses La Vanguardia, Mundo Diario y Avui; los vascos El Correo Español y Deia; y finalmente Diario de Navarra. Seleccionamos estas cabeceras atendiendo a tres criterios: la importancia de su circulación, la representatividad de las tendencias políticas y periodísticas existentes en aquellos años, y la cobertura de distintos ámbitos geográficos ${ }^{8}$. Asimismo, se incluyen

${ }^{5}$ Cfr. McQuAlL, D.: Introducción a la teoría de la comunicación de masas. Barcelona, Paidós, 2000, págs. 116-119.

6 Cfr. GomIs, L.: El medio media: la función política de la prensa. Madrid, Seminarios y Ediciones, 1974, pág. 13; Tuchman, G.: Making News. Nueva York, The Free Press, 1978, pág. 209; ALTHEIDE, D.: An Ecology of Communication: Cultural Formats of Control. Nueva York, Aldine de Gruyter, 1995, pág. 37; PEÑA, E.: Los medios de comunicación como constructores de la realidad. Aproximación teórico-práctica al proceso de mediación, (Tesis de máster s. p.), Universidad de Navarra, 1995, pág. 42.

7 Este artículo es parte de una investigación más amplia en la que se ha estudiado la representación global de Juan Carlos I y de su Monarquía en la prensa española de la transición a partir de 75 eventos históricos. Cfr. ZUGASTI, R.: La forja de una complicidad. Monarquía y prensa en la transición española (1975-1978), Fragua, Madrid, 2007. (En prensa)

8 Para una aproximación a la prensa de la transición, véanse, por ejemplo, ALfÉREZ, A.: Cuarto poder en España. La prensa desde la Ley Fraga 1966. Barcelona, Plaza \& Janés, 1986; BARRERA, C.: Sin Mor- 
como fuentes algunos testimonios personales de periodistas con cargos directivos en los rotativos estudiados.

\section{UNA VINCULACIÓN MANTENIDA HASTA LOS PRIMEROS DÍAS DE REINADO}

El nombramiento de Don Juan Carlos como sucesor de Franco a título de Rey por aprobación de las Cortes, el 22 de julio de 1969, fue uno de los principales acontecimientos que plasmaron en la historia la instauración de la Monarquía del 18 de julio $^{9}$. Aunque el presente artículo fije primordialmente su atención en el periodo abierto tras la muerte de Franco, creemos conveniente mostrar aquí la cobertura periodística concedida al evento acaecido en 1969 por su enorme importancia para el tema tratado y para tener de esta manera un punto de comparación con el discurso periodístico que empleará la prensa tras la proclamación del Rey. El 17 de julio se publicó en el Boletín Oficial del Estado el anuncio de la sesión extraordinaria de las Cortes para el día 22, durante la cual Franco iba a dirigir personalmente un mensaje «en relación con el artículo $6 .^{\circ}$ de la ley de Sucesión en la Jefatura del Estado ${ }^{10}$. Nada más se concretaba en el $B O E$, pero en la mente de todos estaba el nombre del elegido.

Franco, en su discurso ante la sesión extraordinaria de las Cortes, dejó bien claro que la institución que se instauraba era de nuevo cuño, lo que suponía una quiebra del legítimo orden dinástico de sucesión al trono, pues éste recaía en Don Juan de Borbón, padre de Don Juan Carlos:

En este orden creo necesario recordaros que el Reino que nosotros, con el asentimiento de la nación, hemos establecido, nada debe al pasado; nace de aquel acto decisivo del 18 de Julio, que constituye un hecho histórico trascendente que no admite pactos ni condiciones. [...] Se trata, pues, de una instauración y no de una restauración, y sólo después de instaurada la Corona en la persona de un Príncipe comienza el orden regular de sucesión que se refiere en el artículo 11 de la misma ley [de Sucesión] ${ }^{11}$.

Por su parte, el Príncipe también lo afirmó en su inmediatamente posterior discurso de aceptación: "Quiero expresar, en primer lugar, que recibo de Su Excelencia el Jefe del Estado y Generalísimo Franco la legitimidad política surgida el 18

daza. Veinte años de prensa en democracia. Madrid, Temas de Hoy, 1995; BARRERA, C., y ZUGASTI, R.: «La introducción de los valores democráticos en la prensa de la transición española (1975-1978)», en BEnavides Delgado, J., y Fernández Blanco, E.: Valores y medios de comunicación. De la innovación mediática a la creación cultural. Madrid, Edipo, 2001, págs. 109-138.

9 Para un estudio de la prensa ante este nombramiento, coincidente en sus conclusiones con el que aquí se desarrolla, cfr. BARRERA, C.: «La prensa española ante la designación de Don Juan Carlos como sucesor de Franco a título de Rey», Comunicación y Sociedad, vol. VII, núm. 1, 1994, págs. 93109.

10 Tomado de $A B C, 17-\mathrm{VII}-1969$, pág. 21.

11 Tomado de Pueblo, 23-VII-1969, pág. 5. 
de julio de 1936, en medio de tantos sacrificios, de tantos sufrimientos, tristes, pero necesarios, para que nuestra Patria encauzase de nuevo su destino» ${ }^{12}$.

Empezando por los diarios no caracterizados por su monarquismo dinástico, Ya publicó dos editoriales al respecto, uno antes de la sesión de Cortes y otro después. En el primero de ellos mostró diáfanamente su tradicional accidentalismo: «No imponer nada en nombre de la Historia, sino de la conveniencia nacional; no ver en la monarquía un legado del pasado, sino una posible prenda de porvenir; encajarla dentro del marco constitucional vigente» ${ }^{13}$. El segundo editorial, titulado expresivamente «Instauración», reafirmó esta idea, a la vez que hizo una petición a los legitimistas dinásticos:

Téngase en cuenta [...] que desde el punto de vista nacional, e incluso desde el de la propia monarquía, ésta, la institución, que está para servir a la nación, tiene a su vez preferencia plena sobre las personas ${ }^{14}$.

Lo anterior indica cómo Ya aceptó la Monarquía del 18 de julio sin inconvenientes, por considerar que era una medida positiva para España y un paso más en la institucionalización del Régimen.

La posición de Pueblo la marcó su director, Emilio Romero, con uno de sus «gallitos». En él aplaudió la decisión tomada al considerarla la única posible y por ser una instauración querida por Franco, y no la restauración de la vieja institución derribada en 1931. Romero no desaprovechó la ocasión para fustigar a los monárquicos y marcar diferencias entre el Príncipe y su padre:

Don Juan de Borbón y Battenberg, ante el cúmulo de errores de sus monárquicos efectivos y credencializados, una vez pasada la contrariedad de estos instantes, tendrá que hacer dos reconocimientos expresos, aunque amargos, de gratitud y de satisfacción. O el alma humana es también obstinada. La gratitud a Franco por la instauración de una monarquía, cuya corona ha puesto en las sienes de su hijo, en medio de un ambiente de indiferencia general en el país hacia las formas de gobierno, principalmente hacia la forma monárquica. $Y$ satisfacción y orgullo por su hijo, el Príncipe Juan Carlos, que en lugar de haber adoptado una fácil y afectiva actitud de identificación con la empresa monárquica de su padre, ha realizado la difícil tarea de ofrecer a la institución monárquica otra posibilidad, mediante el respeto a un sistema político, y con una prudencia y una discreción admirables para que su figura en el país no se acompañara nunca de actos ligeros, o impacientes, o detonantes ${ }^{15}$.

12 Tomado de Pueblo, 24-VII-1969, pág. 5.

13 Ya, 21-VII-1969, pág. 7: «Una constante aspiración» (editorial).

14 Ya, 23-VII-1969, pág. 5: «Instauración» (editorial).

15 Pueblo, 23-VII-1969, pág. 3: «La única monarquía posible» (artículo de opinión de Emilio Romero). También desde las páginas del rotativo sindical, Martínez Reverte, una de sus plumas habituales, dejó bien clara la naturaleza de la nueva Corona en las primeras líneas de su columna: «España tiene Príncipe heredero. Su título, de nuevo cuño, Príncipe de España, y en el marco de la Monarquía del Movimiento». Pueblo, 24-VII-1969, pág. 2: «La criba» (columna de Martínez Reverte). 
El Alcázar, ante el anuncio de la convocatoria extraordinaria de Cortes, adoptó un tono contundente para mostrar cuál era la legitimidad de la Monarquía que se instauraba:

Nunca, y menos ahora, se ha pensado en una vieja restauración a lo Sagunto, sino en una etapa auténticamente nueva. Ni un paso más atrás del 18 de Julio, ni una mirada más allá. La legitimidad es del pueblo y sólo a él pertenece. España no es una huerta familiar que se regale o se deje en herencia, y el 18 de Julio tiene en sí mismo, como magnitud histórica, toda la carga necesaria para elevar legitimidades y títulos de legalidad. [...] Y no existe otra puerta de entrada que esa del 18 de julio y su carga de legitimidades, selladas con sangre y con sacrificio ${ }^{16}$.

Diario de Navarra, en un editorial referido a la conmemoración del 18 de julio, vinculó esta fecha con el inminente nombramiento de Don Juan Carlos como sucesor, algo que se consideraba muy probable: «La fecha histórica que nació al calor de un sacrificio popular se corona hoy con verdadera esperanza ante un futuro prometedor ${ }^{17}$.

Todos estos diarios no señalados en la defensa de la Monarquía dinástica titularon asimismo de una manera muy significativa aquellas informaciones referidas al nombramiento del Príncipe. A través de los titulares se destacó que, efectivamente, se trataba de una instauración basada en la legitimidad del 18 de julio. Así, por ejemplo, Pueblo tituló dos informaciones en portada, respectivamente: «Nada debemos al pasado (afirmación de Franco en las Cortes) ${ }^{18} \mathrm{y}$ «Compromiso con el Régimen (sin ambigüedades)»19. Diario de Navarra tituló de forma parecida: «El Reino que hemos establecido nada debe al pasado, nace de aquel 18 de julio ${ }^{20}$. Ya subtituló de la siguiente manera la noticia referida a la designación: «Franco, al proponerlo a las Cortes, dice que se trata de una instauración y no de una restauración. El Reino no debe nada al pasado „21. Diario Femenino, antecedente de Mundo Diario, destacó en un subtítulo que se trataba de «una instauración, no una restauración» ${ }^{22}$. Más exhaustivos fueron el titular de El Alcázar («Esta es la Monarquía del Movimiento Nacional») y sus subtítulos: «El Reino que hemos establecido nada debe al pasado. Nace de un hecho histórico y trascendente -el 18 de julio- que no admite pactos ni condiciones. Se trata, pues, de una instauración y no de una restauración ${ }^{23}$.

Por otra parte, estaban aquellos periódicos a los que tradicionalmente se les había atribuido un talante monárquico ${ }^{24}$. Como «un paso lógico» valoró El Correo

16 El Alcázar, 22-VII-1969, pág. 2: «Lealtad» (editorial).

17 Diario de Navarra, 18-VII-1969, pág. 1: «Ante el 18 de julio» (editorial).

18 Pueblo, 23-VII-1969, pág. 1.

19 Pueblo, 24-VII-1969, pág. 1.

20 Diario de Navarra, 23-VII-1969, pág. 1.

21 Ya, 22-VII-1969, pág. 5.

22 Diario Femenino, 23-VII-1969, pág. 13.

${ }^{23}$ El Alcázar, 23-VII-1969, pág. 3.

${ }^{24}$ Desde el Gobierno se inició una campaña para garantizar la postura editorial favorable de los más representativos órganos monárquicos. Manuel Fraga, como titular de la cartera de Información, se en- 
Español la decisión del Generalísimo. Además dejó claro que se trataba de una «instauración monárquica», un avance más «en el proceso institucional abierto hace ya más de 20 años» con la Ley de Sucesión ${ }^{25}$.

El catalán La Vanguardia no tuvo problemas en apoyar la decisión del Jefe del Estado y en aceptar la instauración de una nueva Monarquía en la persona de Don Juan Carlos. Así, el mismo día de la sesión de Cortes saludó con «emoción y con júbilo el advenimiento de la suprema Institución que Dios quiera que presida muchos años de paz y de unidad entre todos los españoles ${ }^{26}$. La Vanguardia hizo ver, y aceptó, que se trataba de la instauración de una institución basada en el 18 de julio, pero de un modo mucho más mesurado que cabeceras como Pueblo o El Alcázar. Además, intentó dotar al Príncipe de algo de legitimidad dinástica:

Por razón de su estirpe, la persona de Don Juan Carlos encarna un acervo de sagradas tradiciones que generaciones y generaciones de españoles depositaron en la institución regia, y a las cuales, en nuestra edad, se ha añadido el inmenso patrimonio de sacrificios y esperanzas entrañado en el Movimiento Nacional ${ }^{27}$.

El diario madrileño $A B C$, de indiscutible solera legitimista, publicó un día antes de la reunión en el palacio de la Carrera de San Jerónimo un editorial expresivamente titulado "Con la sangre de nuestros Reyes» en el que acató de forma explícita el salto en el orden dinástico. Era, en definitiva, el apoyo de la más significada cabecera monárquica a la decisión de Franco. $A B C$ arropó al Príncipe y, de forma similar a La Vanguardia, hizo ver que de alguna forma también poseía legitimidad dinástica por ser el heredero de Don Juan:

Aunque se desconoce el mensaje del Jefe del Estado a la nación, hay sobrados elementos de juicio para saber que la designación recaerá en el Príncipe Don Juan Carlos de Borbón, hijo único varón del Conde de Barcelona, a su vez depositario de los derechos hereditarios, por haber abdicado a su favor, meses antes de su muerte, Su Majestad el Rey Don Alfonso XIII.

Conocedores de las sobresalientes condiciones personales del Príncipe Don Juan Carlos de Borbón, de su profundo y estricto sentido del deber y de su gran amor a España, pedimos a Dios que ilumine sus pasos en el difícil camino del más sacrificado servicio a la grandeza de la Patria.

trevistó con los Luca de Tena para asegurar la respuesta positiva de $A B C$. Cfr. FraGA, M.: Memoria breve de una vida pública. Barcelona, Planeta, 1987, págs. 248-250. Por su parte, Laureano López Rodó, como ministro más distinguido en la defensa de la candidatura de Don Juan Carlos, habló con Xavier de Echarri y con Antonio Fontán, directores, respectivamente, de La Vanguardia y de Madrid. Cfr. LóPEZ Rodó, L.: Memorias. Años decisivos. Barcelona, Plaza \& Janés, 1991, págs. 457-459.

25 El Correo Español, 24-VII-1969, pág. 36: «Un paso lógico» (editorial).

26 La Vanguardia, 22-VII-1969, pág. 5: «Monarquía representativa» (editorial).

27 La Vanguardia, 24-VII-1969, pág. 5: «Una voz juvenil, progresiva, ilusionada» (editorial). Una argumentación similar ofreció Julio Trenas en su crónica de la sesión parlamentaria: «La mano conductora de Francisco Franco ha hecho posible que toda la proeza recuperadora de la patria, signada un 18 de Julio inolvidable, mantenga este timbre de continuidad en la estirpe y de fidelidad, al propio tiempo, al mandato de unos Principios Fundamentales que el país aceptó en libre uso de sus derechos cívicos". La Vanguardia, 24-VII-1969, pág. 6: «Broche de oro» (crónica de Julio Trenas). 
No podía, sin embargo, $A B C$ olvidar su vieja lealtad hacia Don Juan de Borbón y a él dedicó las emocionadas últimas líneas del editorial:

Hecha sincera súplica a Dios por el Príncipe, nuestro corazón y nuestro pensamiento se vuelven, con entrañable emoción, hacia esa pequeña villa, de españolísimo nombre, donde, en un pueblecito portugués, vive, desde hace tantos años, en apartamiento sobrellevado con ejemplar entereza, el hombre de quien Don Juan Carlos ha recibido la enseñanza y ejemplo de las más altas virtudes y quien, por el hecho, excelso siempre, de la paternidad, le ha transmitido la sangre de nuestros Reyes ${ }^{28}$.

Pese al acatamiento de $A B C$, su director, Torcuato Luca de Tena, procurador en Cortes, votó «no» a la designación de Don Juan Carlos guiado por su fidelidad personal hacia Don Juan ${ }^{29}$. Él mismo explicó su voto negativo al considerar «la Monarquía como la más perfecta Institución para España» y el «Orden Sucesorio como la mayor y más perfecta virtud de la Monarquía». Ante la pregunta de cuál iba a ser su actitud a partir de aquel momento, Luca de Tena contestó lo siguiente:

Reconocer la decisión histórica que ha sido tomada y sacrificar mi pesadumbre al acatamiento y servicio de lo que, con mi voto en contra han resuelto las Cortes. Hay que entender, por tanto, mi voto como formulado en defensa de la pureza de la Institución que encarnará algún día -y confío que para gloria y grandeza de España- el Príncipe Don Juan Carlos ${ }^{30}$.

Como hemos puesto de manifiesto, todos los órganos de prensa analizados acataron, con mayor o menor énfasis, la decisión de Franco de nombrar sucesor suyo a título de Rey a Don Juan Carlos ${ }^{31}$.

Las referencias a la legitimidad del 18 de julio en que se basaba la Monarquía de Don Juan Carlos encontraron cabida, de nuevo, con motivo de las dos interini-

28 ABC, 21-VII-1969, pág. 13: “Con la sangre de nuestros Reyes» (editorial). La Vanguardia reprodujo dichas frases de recuerdo a Don Juan. Cfr. La Vanguardia, 23-VII-1969, pág. 3: «Seguridad ante el futuro" (editorial). Sobre los avatares relacionados con este editorial, cfr. OLMOS, V.: Historia del $A B C$. 100 años clave en la historia de España, Barcelona, Plaza \& Janés, 2002, págs. 443-456.

29 El Príncipe supo apreciar el verdadero valor del voto negativo de Torcuato Luca de Tena, y así se lo mostró al director de $A B C$ al día siguiente en La Zarzuela: «Quiero agradecerte lo que hiciste ayer por mi padre, votando que no». LóPEZ Rodó, L.: La larga marcha hacia la monarquía. Barcelona, Noguer, 1977, pág. 378.

${ }^{30} A B C, 23-\mathrm{VII}-1969$, pág. 22: «Torcuato Luca de Tena: 'El orden sucesorio es la mayor y más perfecta virtud de la Monarquía. Acato la decisión histórica de las Cortes adoptada con mi voto en contra'» (entrevista sin firma).

${ }^{31}$ Pese a no ser uno de los diarios tomados como muestra para este trabajo, creemos conveniente mencionar la única nota discrepante en la prensa respecto a la decisión de Franco. El donjuanista Madrid, dirigido por Antonio Fontán, publicó un editorial titulado «Ante las Cortes del 22 de julio». Este artículo, aparecido en portada, abogaba por una extraña pero legal solución: la designación de Don Juan Carlos, pero a título de regente, ya que la alternativa que triunfó presentaba «el inconveniente de cerrar — contra lo ocurrido hasta ahora- toda posibilidad institucional y personal de opción». El mencionado inconveniente hacía velada referencia a la negación de cualquier posibilidad para Don Juan en el futuro. Madrid, 21-VII1969, pág. 1: «Ante las Cortes del 22 de julio» (editorial). Sobre este artículo y sus vicisitudes, cfr. BARRERA, C.: El diario Madrid: realidad y símbolo de una época. Pamplona, Eunsa, 1995, págs. 362-367. 
dades del Príncipe en la Jefatura del Estado ${ }^{32}$. Y además aparecieron en aquellos diarios que más habían destacado el origen franquista de la institución, es decir, Pueblo y El Alcázar. El periódico sindical, al cumplirse cinco años del nombramiento del Príncipe como sucesor, recordó las palabras de Franco:

El Jefe del Estado, a la vez que definía la Sucesión como encarnada en una Monarquía de nueva planta, cuya raíz de legitimidad era el 18 de Julio, expresaba la naturaleza nueva de esa misma Monarquía, en el sentido de que nacía sin deuda alguna con compromisos pasados ni con situaciones homologables ${ }^{33}$.

Por su parte, El Alcázar también recordó en varios artículos cuál era el cimiento sobre el que se asentaba el cada vez más próximo reinado de Don Juan Carlos. Sirva como ejemplo lo afirmado en un editorial sobre el futuro político:

Si en el orden institucional no existe duda cara al futuro, tampoco lo existe en el doctrinal, ya que el carácter permanente e inalterable de los Principios del Movimiento garantiza la continuidad del espíritu del 18 de julio que inspira el sistema político ${ }^{34}$.

Tras la muerte de Franco y con motivo del discurso ante las Cortes del recién proclamado Rey, el 22 de noviembre de 1975, cabe comentar un aspecto destacado por varios periódicos, debido a lo que tiene de conexión del Monarca con la figura de su antecesor en la Jefatura del Estado. Dicho aspecto son las referencias que varios diarios hicieron al párrafo del testamento político de Franco en el que éste pedía que se apoyara a Don Juan Carlos $^{35}$. $A B C$ publicó una crónica en la que reconocía que en las Cortes había procuradores que habían respondido «al ¡Viva! del presidente del Consejo de Regencia por acatar el mandato contenido en ese estremecedor documento póstumo del Caudillo leído por Arias Navarro ante las cámaras de televisión» ${ }^{36}$. Pueblo, por su lado, destacó en un titular de portada, a grandes caracteres, la parte del testamento referida al nuevo Rey ${ }^{37}$. Diario de Navarra y Ya hicieron referencia al mencionado párrafo en sendos editoriales. Así, el periódico navarro cerró su artículo con la reproducción de las palabras de

${ }^{32}$ El Príncipe asumió provisionalmente la Jefatura del Estado por enfermedad de Franco el 19 de julio de 1974 y el 30 de octubre de 1975. Con respecto a la última interinidad, Franco no reasumió sus poderes, pues murió el 20 de noviembre.

33 Pueblo, 22-VII-1974, pág. 3: «Cinco años» (editorial). Para una referencia similar a la legitimidad de la Monarquía en el mismo diario, cfr. Pueblo, 31-X-1975, pág. 3: «Don Juan Carlos asume la Jefatura del Estado" (editorial).

${ }^{34}$ El Alcázar, 5-IX-1974, pág. 2: "Cara al futuro» (editorial). Para otros recordatorios en el diario de DYRSA del 18 de julio como acto fundador de la nueva Monarquía, cfr. El Alcázar, 20-VII-1974, pág. 5: «Legitimidad política del 18 de julio»; El Alcázar, 24-VII-1974, pág. 5: «Sesión plenaria» (crónica de Luis Montes); El Alcázar, 31-X-1975, pág. 1: «Entró en funciones» (artículo de opinión de Antonio Gibello).

${ }_{35}$ El párrafo decía así: «Os pido que [...] rodeéis a don Juan Carlos de Borbón del mismo afecto y lealtad que a mí me habéis brindado y le prestéis en todo momento el mismo apoyo y colaboración que de vosotros he tenido". BARDAvío, J., y Sinova, J.: Todo Franco. Franquismo y antifranquismo de la a A la Z. Barcelona, Plaza \& Janés, 2000, pág. 632-633.

${ }^{36} A B C, 24-\mathrm{XI}-1975$, pág. 39: «Don Juan Carlos I, Rey» (crónica sin firma).

${ }^{37}$ Cfr. Pueblo, 21-XI-1975, pág. 1. 
Franco calificándolas de «petición muy concreta» ${ }^{38}$. El diario de La Editorial Católica comenzó su editorial con la siguiente idea:

El postrer servicio de Franco al futuro ha sido la apelación al pueblo español que hace en su testamento político para que se agrupe en torno al Rey como lo hizo con él. Podríamos añadir que, aún después de muerto, Franco ha ganado su última batalla, que ha sido ofrecer al Rey las masas que en espontáneo, sincero, conmovedor plebiscito han acudido a darle su fervoroso adiós ${ }^{39}$.

En las anteriores valoraciones periodísticas se observa un interés por ganar para el Rey la estima de los franquistas hacia su Caudillo, y qué mejor forma de hacerlo que destacar la propia petición de Franco. Se puede afirmar que los diarios mencionados buscaron un traspaso de afecto de Franco al Rey mediante alusiones al testamento en artículos referidos al discurso con el que el Monarca iniciaba su entonces incierta andadura. Sobre la valoración que tenían los españoles de la figura del Generalísimo a la muerte de éste, puede ser ilustrativa una encuesta nacional de ICSA publicada el 22 de noviembre de 1975. En ella, el 53\% de los encuestados afirmaron que la muerte había supuesto dolor y pena, y el $29 \%$ aseguraron que era una pérdida irreparable. Las respuestas que parecían conllevar una valoración negativa sobre el dictador (su muerte había llevado aparejada preocupación por el futuro, indiferencia y otras respuestas) sumaban tan sólo un $18 \%{ }^{40}$.

Buena parte de los periódicos dieron relevancia al juramento, previo a la proclamación como Rey, por el que Don Juan Carlos hizo pública su lealtad a las Leyes Fundamentales y a los Principios del Movimiento ${ }^{41}$. Sin duda fue éste el acto que de forma más explícita vinculaba al nuevo Rey con la Monarquía instaurada, es decir, aquélla cuya fuente de legalidad procedía del 18 de julio y de la victoria franquista en la Guerra Civil. Varios rotativos destacaron las palabras pronunciadas por Don Juan Carlos mediante sumarios $(\mathrm{Ya})^{42}$, mediante la publicación en grandes caracteres de todo el ritual de la jura (La Vanguardia) ${ }^{43}$, o mediante titulares (Diario de Navarra) ${ }^{44}$. Mención aparte merece El Alcázar, ya que no sólo distinguió el juramento de Don Juan Carlos mediante un sumario muy destacado tipográficamente y un titular de portada ${ }^{45}$, sino que también publicó un recuadro con el jura-

38 Cfr. Diario de Navarra, 23-XI-1975, pág. 1: «Un orden nuevo» (editorial).

39 Ya, 25-XI-1975, pág. 7: «Las colas, factor de primera magnitud» (editorial).

40 Cfr. LÓPEZ PINTOR, R.: «El estado de la opinión pública española y la transición a la democracia», Revista Española de Investigaciones Sociológicas, núm. 13, 1981, pág. 40.

41 Don Juan Carlos empleó la siguiente fórmula: «Juro por Dios y sobre los Santos Evangelios cumplir y hacer cumplir las Leyes Fundamentales del Reino y guardar lealtad a los Principios que informan el Movimiento Nacional». Tomado de Ya, 24-XI-1975, pág. 9.

42 Ya, 24-XI-1975, pág. 9. Este periódico también destacó mediante un titular que la Monarquía que comenzaba era de nuevo cuño: «Instauración de la Monarquía». Ya, 22-XI-1975, págs. 12-13.

43 La Vanguardia, 23-XI-1975, pág. 7.

44 Diario de Navarra, 22-XI-1975, pág. 14.

45 Respectivamente, El Alcázar, 22-XI-1975, pág. 8 y El Alcázar, 22-XI-1975, pág. 1. 
mento prestado por Don Juan Carlos en 1969 al aceptar el nombramiento como sucesor de Franco a título de Rey ${ }^{46}$.

Este interés del órgano de la Confederación Nacional de Combatientes por remarcar el origen por el que Don Juan Carlos accedía al trono se plasmó también en un editorial que aprovechó una frase del discurso del Rey ante las Cortes para sacar a relucir la legitimidad de la nueva Monarquía:

'Deseo ser capaz de ser fiel defensor de la constitución', es la frase que reafirma la legitimidad del nuevo rey y renueva la esperanza de este pueblo que supo ser fiel a Franco y lo será, ahora, al nuevo Jefe del Estado, nacido del consenso popular a la decisión del Caudillo, cuando designó al actual rey como su sucesor ${ }^{47}$.

No fue el anterior el único editorial publicado por El Alcázar que insistía en la misma idea, en recalcar que la Corona que se instauraba era una continuación del Régimen que la había hecho posible:

El pueblo ha sido unánime al improvisar su respuesta sobre lo que esperaba del Rey nuevo: continuar y mejorar la obra de Franco. ¿Cabe más tentador y comprometido programa? ${ }^{48}$.

Además, El Alcázar no desaprovechó la oportunidad de criticar otras opiniones periodísticas a su parecer demasiado osadas, y para ello volvió a recalcar la continuidad del nuevo reinado con el franquismo:

La lectura de algunos comentarios publicados estos días produce asombro. De creerlos, resultaría que en España no se ha producido una sucesión en la Jefatura del Estado, con arreglo a previsiones que hace años pertenecen a nuestra legislación fundamental, sino una especie de revolución, con lo que todo ha cambiado. En España, en efecto, estos días han ocurrido cosas importantes, como son la muerte de un Caudillo amado de su pueblo, que durante cuarenta años ha regido venturosamente la vida de la nación, la proclamación de un Rey, hace años nombrado sucesor, y que ya con anterioridad había ejercido, en momentos difíciles, las funciones de Jefe de Estado, la multitudinaria muestra de adhesión del pueblo al Régimen del 18 de julio, manifestada, primero, en el dolor por la muerte del hombre que lo encarnaba, y luego en la entusiasta acogida al Rey que le ha sucedido ${ }^{49}$.

En el primer mensaje a los españoles, Juan Carlos I dedicó un párrafo a recordar con «respeto y gratitud ${ }^{50}$ la figura de Francisco Franco, su antecesor en la

46 El Alcázar, 22-XI-1975, pág. 4. La fórmula de juramento en aquella ocasión fue: «Juro lealtad al Caudillo, a los Principios Fundamentales del Movimiento y demás Leyes Fundamentales del Reino».

47 El Alcázar, 22-XI-1975, pág. 9: «Juan Carlos, rey» (editorial).

48 El Alcázar, 24-XI-1975, pág. 3: «El pueblo, con el rey» (editorial).

49 El Alcázar, 29-XI-1975, pág. 2: «Espectáculo grotesco» (editorial). La misma idea apareció en un artículo publicado aquel día: «La sucesión en la Jefatura del Estado no ha supuesto ningún cambio. [...] Es, en suma, la continuidad del Régimen que se había constituido en Reino allá por el mes de julio de 1947». El Alcázar, 29-XI-1975, pág. 2: «La voluntad popular» (artículo de opinión de «Barbacana»).

50 Tomado de $A B C, 24-X I-1975$, pág. 3 de huecograbado. 
Jefatura del Estado y quien había hecho posible la instauración monárquica en su persona. Estas palabras del recién proclamado Rey fueron destacadas por varios diarios. $A B C$ dedicó toda una página a reproducir ese párrafo, al que tituló «En recuerdo de Franco ${ }^{51}$. El Alcázar, por su parte, subrayó en un editorial la evocación del Rey al Caudillo52. Algo similar hizo La Vanguardia al calificar, también en un editorial, la mención a Franco como una «expresión de profunda gratitud»53. El diario $Y a$ lo hizo mediante un sumario en el que se reprodujeron las palabras del Rey ${ }^{54}$, y Diario de Navarra resaltó en el subtítulo de su crónica del acto de proclamación que «la ovación más larga, dedicada al recuerdo de Franco»55.

Buena parte de las cabeceras, como se ha visto, recogió y resaltó la referencia del Rey a Franco en su discurso, ofreciendo así una cierta identificación entre ambas figuras. A este respecto cabe destacar un editorial de El Correo Español donde se afirmó que la andadura de la Corona iba a ser «posible a partir de la herencia de paz y prosperidad» recibida, "como precioso legado, del Caudillo Franco» ${ }^{56}$.

En otro orden de cosas, aunque relacionado con lo anterior, el discurso de Juan Carlos I ante las Cortes suscitó la aparición de la Guerra Civil en algunos comentarios periodísticos, si bien el Soberano no hizo mención a ella en su mensaje. Fue una omisión significativa, ya que, al fin y al cabo, la contienda era el origen de la legitimidad franquista y, por tanto, también de la Monarquía instaurada. Representativos de la aparición del recuerdo de la Guerra Civil en la prensa fueron sendos editoriales de Pueblo y de Mundo Diario. El periódico madrileño dijo así:

El Rey aseguró que 'hoy comienza una nueva etapa de la Historia de España'. Todo parece indicar que va a ser así, en efecto. Ahora bien: comenzar una etapa significa clausurar otra. El Rey clausuró con sus palabras, positivamente, y con todos los reconocimientos deseables, la España de la guerra civil. El día 22 de noviembre de 1975 acabó la guerra civil ${ }^{57}$.

Mundo Diario afirmó que el espíritu del mensaje, conjugado con aquellas decisiones que cancelaran «toda tensión y enfrentamiento debidos a acontecimientos pasados, en especial la lejana guerra civil», iba a servir para que la sociedad obtuviera «la total práctica de los derechos políticos tantas veces reclamada»58. La diferencia estribaba en que Pueblo se mostró más conformista: tan sólo con el discurso dio por cerrada la Guerra. Para el diario catalán, el final de las consecuencias del conflicto sería el fruto de decisiones futuras que parecían incumbir al Rey. Aho-

$51 A B C, 24-\mathrm{XI}-1975$, pág. 13 de huecograbado. El párrafo se reprodujo sobre el fondo de una fotografía de los procuradores en Cortes escuchando el discurso real.

52 Cfr. El Alcázar, 22-XI-1975, pág. 9: «Juan Carlos, Rey» (editorial).

53 La Vanguardia, 23-XI-1975, pág. 7: «Al servicio del pueblo» (editorial).

54 Cfr. Ya, 24-XI-1975, pág. 5.

55 Diario de Navarra, 23-XI-1975, pág. 10: «Cinco veces fue interrumpido el discurso del Rey» (crónica de Cifra).

56 El Correo Español, 23-XI-1975, pág. 60: «El mensaje del Rey» (editorial).

57 Pueblo, 24-XI-1975, pág. 3: «El mensaje de la Corona» (editorial).

58 Mundo Diario, 23-XI-1975, pág. 3: «Ganar el futuro» (editorial). 
ra bien, las referencias al enfrentamiento bélico en ambos casos se hicieron con el propósito de buscar la reconciliación y de mostrar que con Juan Carlos I se abría una nueva etapa que cerraría las heridas de la confrontación, y no con el objetivo de resaltar que ése era el origen de la Monarquía del 18 de julio ${ }^{59}$. No compartía esta idea el pamplonés García Serrano, uno de los más destacados columnistas de El Alcázar, y de hecho el editorial de Pueblo mereció un ataque en su columna «Dietario personal»:

Todo es posible. Incluso el diario Pueblo acaba de realizar una profunda investigación histórica que le ha permitido precisar la fecha exacta del fin de la Guerra de España, que no es el 1 de abril de 1939, como aseguró, incluso con su firma, el Caudillo, sino - ya se puede decir sin miedo- el 22 de noviembre de 1975, sin duda porque el Caudillo mantuvo a España en un perpetuo estado de guerra civil no se sabe si por capricho o por fomentar la novelería del turismo ${ }^{60}$.

A los pocos días, el 25 de noviembre de 1975, se decretó un indulto general con motivo de la proclamación del Rey. En el preámbulo del decreto se afirmaba que la medida constituía también un homenaje a la figura del recientemente fallecido Franco ${ }^{61}$. Tres diarios - El Alcázar y Pueblo- destacaron con sumarios que el indulto regio era también un homenaje a Franco, con lo que en cierta forma la medida se impregnó del recuerdo al anterior Jefe del Estado ${ }^{62}$. El Alcázar también hizo referencia a esta circunstancia en un editorial63, y El Correo Español afirmó en otro que el indulto regio era «una generosa medida de perdón en consonancia con el testamento de Franco» ${ }^{64}$.

\section{SE DESVANECE LA IDENTIFICACIÓN}

A partir de estos primeros momentos tras la muerte de Franco, la vinculación entre la Monarquía de Juan Carlos I y la legitimidad del 18 de julio que la hizo po-

59 Las partes del discurso regio que parecían apuntar a un aperturismo político fueron las alusiones a «una nueva etapa en la historia de España», caracterizada por «un efectivo consenso de concordia nacional». Asimismo, Don Juan Carlos mencionó la necesidad de «perfeccionamientos profundos» y aludió a la «participación de todos en los foros de decisión, en los medios de información, en los diversos niveles educativos y en el control de la riqueza nacional». Tomado de ARMADA, A.: Al servicio de la Corona. Barcelona, Planeta, 1983, págs. 194-196.

60 El Alcázar, 27-XI-1975, pág. 3: «Dietario personal» (columna de Rafael García Serrano). Obsérvese cómo el columnista eludió en una ocasión el término «Guerra Civil» y empleó «Guerra de España». El primero era difícil de aceptar para los partidarios más acérrimos del Régimen franquista, que preferían hablar de «Guerra de Liberación» o, más neutramente, de «Guerra de España». Sobre las distintas denominaciones de la guerra y sus connotaciones, cfr. AGUILAR, P.: Memoria y olvido de la guerra civil española. Madrid, Alianza, 1996, págs. 193-198.

61 El preámbulo decía así: «La promulgación de este indulto general constituye asimismo un homenaje a la memoria de la egregia figura del Generalísimo Franco (q. e. G. e.), artífice del progresivo desarrollo en la Paz de que ha disfrutado España en las últimas cuatro décadas, durante las cuales otorgó once indultos generales e innumerables indultos particulares». Tomado de $A B C, 26-\mathrm{XI}-1975$, págs. 87-88.

62 Cfr. El Alcázar, 26-XI-1975, pág. 1; Pueblo, 26-XI-1975, pág. 1.

63 Cfr. El Alcázar, 8-XII-1975, pág. 2: «Provocación» (editorial).

64 El Correo Español, 28-XI-1975, pág. 28: «Comienza el reinado» (editorial). 
sible desapareció de la prensa, con la excepción de El Alcázar. Desde entonces, el recuerdo de Franco y de su Régimen en relación con la Monarquía apareció únicamente con motivo de los hitos que suponían los sucesivos aniversarios de la muerte del dictador.

El 20 de noviembre de 1976, con la Ley para la Reforma Política recién aprobada en las Cortes, se conmemoró el primero y se celebró un funeral en el Valle de los Caídos que fue presidido por los Reyes. Este hecho fue mostrado por la prensa en sus titulares con lo que, en cierta forma, se vinculó la Corona al franquismo o al menos a la reciente memoria de Franco ${ }^{65}$.

El aniversario mereció también varios comentarios periodísticos, y algunos de ellos mencionaron a Don Juan Carlos. El Alcázar publicó dos artículos que hacían referencia al Rey conectándolo con el franquismo. En el primero de ellos, Higinio París sostuvo que el pueblo aceptó con entusiasmo la proclamación de Don Juan Carlos porque «la interpretó como una continuidad del Régimen de Franco» ${ }^{66}$. El segundo fue firmado por "Jerjes» y en él se hablaba de la necesidad de proteger al Rey y a la Corona de la subversión porque el Caudillo así lo pidió y porque fue él quien instauró la Monarquía ${ }^{67}$. $A B C$, por su parte, publicó un editorial laudatorio a Franco y muy crítico con la Segunda República en el que se afirmaba lo siguiente: «Lo que era una República en ruina jurídica se convirtió en una Monarquía robusta y legítimamente estructurada»68. En el mismo diario, José María Ruiz Gallardón escribió un artículo en el que, entre otras cosas, definió el franquismo como «cuarenta años de paz que nos dieron como fruto inmediato una Monarquía estable y fecunda, amparo de cada uno de los españoles ${ }^{69}$. Estos artículos tanto de El Alcázar como de $A B C$ vincularon al Rey con el franquismo al dejar claro que la Monarquía de Don Juan Carlos fue producto del Régimen de Franco, un Régimen que, además, en ambos rotativos estaba positivamente valorado. Una imagen benigna del franquismo, aunque en un tono mucho más neutro, se desprendía asimismo de un editorial de $\mathrm{Ya}$ en el que se instaba a no utilizar la figura de Franco

65 Cfr. El Alcázar, 20-XI-1976, pág. 1: «Ha sido presidido por S. M. el Rey»; ABC, 21-XI-1976, pág. 1: «Los Reyes presidieron el solemne funeral en el Valle de los Caídos»; Pueblo, 20-XI-1976, pág. 1: «Solemne funeral presidido por los Reyes de España»; Ya, 22-XI-1976, pág. 3: «Los Reyes presidieron los funerales por Franco»; El País, 21-XI-1976, pág. 1: "Los Reyes, en el funeral por Franco»; La Vanguardia, 21-XI-1976, pág. 5: «Funeral en el Valle de los Caídos con asistencia de SS. MM. Los Reyes [...]»; Mundo Diario, 21-XI-1976, pág. 4: «Los Reyes oraron por Franco»; Avui, 21-XI-1976, pág. 1: «Reis i govern al Valle de los Caídos i unes 100.000 persones a la plaça d'Oriente»; El Correo Español, 21-XI1976, pág. 1: «Asistieron los Reyes y la señora de Meirás con su familia»; Diario de Navarra, 21-XI-1976, pág. 1: «Asistieron los Reyes, el Gobierno y la viuda del Generalísimo». Obsérvese cómo muchos de los diarios publicaron además su titular en portada.

66 El Alcázar, 20-XI-1976, pág. 3: «El último recuerdo de Franco» (artículo de opinión de Higinio París).

67 Cfr. El Alcázar, 20-XI-1976, pág. 3: «¡Francisco Franco Bahamonde! ¡i¡Presente!!!» (artículo de opinión de «Jerjes»). Tras el seudónimo de «Jerjes» estaba el general Luis Cano Portal. Cfr. LóPEZ DE ZuAzo, A.: Catálogo de periodistas españoles del siglo xx. Madrid, Facultad de Ciencias de la Información, 1981, pág. 296.

68 ABC, 20-XI-1976, pág. 3: «Franco» (editorial).

$69 A B C, 20-\mathrm{XI}-1976$, pág. 5: «Primer aniversario: asumir la historia» (artículo de opinión de José María Ruiz Gallardón). 
para dividir a los españoles, ya que el propio Caudillo pidió en su testamento que todos los españoles permanecieran unidos en torno al Rey ${ }^{70}$.

La Vanguardia, por otro lado, publicó un editorial en el que, un año después de la muerte de Franco, el franquismo no salía muy bien parado - se le calificaba, por ejemplo, de "dictadura»- y se hablaba del Rey como corrector de algunos aspectos negativos del Régimen:

El Rey ha echado sobre sus espaldas de patriota y de soldado la carga abrumadora de corregir la incomunicación y el aislamiento de España en sus dos dimensiones, internacional y también intranacional, y lo está consiguiendo porque ¿existe alguna institución que sea por naturaleza tan característicamente transnacional como la Monarquía?71.

La postura de La Vanguardia ante el franquismo plasmada en el editorial anterior, en palpable discordancia con otras valoraciones anteriores, es explicada por el que fuera subdirector del diario barcelonés:

La sociedad lo pedía, había un hartazgo nacional después de cuarenta años de franquismo. Entonces, tuvimos que pulsar la opinión y seguirla. Además, en Cataluña el franquismo había perseguido el catalanismo y la cultura catalana. La sociedad catalana tenía en esto cuentas pendientes ${ }^{72}$.

El País también hizo referencia al Rey en un editorial que constituyó una crítica durísima al franquismo en todos sus aspectos. Para este periódico nuevo, que nacía sin vinculaciones con el Régimen, la Monarquía heredó «una situación social, política y económica tan deteriorada que inevitablemente el camino hacia la democracia» se veía «a diario obstaculizado». El mismo editorial intentó desdibujar la representación de Don Juan Carlos como sucesor de Franco, ya que el Rey pretendía devolver el poder heredado al pueblo, lo que supuso potenciar la imagen democratizadora del Monarca:

La sucesión formal en los órganos del Estado y en la Jefatura del mismo no quiere decir que el poder de Franco haya tenido sucesor. Por eso la Monarquía promete ahora la devolución de su soberanía al pueblo español, a fin de que el poder resida en las instituciones verdaderamente representativas de ese pueblo ${ }^{73}$.

En otro orden de cosas, ese 20 de noviembre tuvo lugar en la Plaza de Oriente de Madrid una multitudinaria concentración en memoria del Caudillo. Algunos manifestantes corearon gritos y consignas en contra de los Reyes como, por ejemplo, «Juan Carlos, Sofía, el pueblo no se fía», o silbaron durante la lectura del testamento político de Franco cuando éste se refería a Don Juan Carlos. Tan

70 Cfr. Ya, 20-XI-1976, pág. 7: «Primer aniversario» (editorial).

71 La Vanguardia, 20-XI-1976, pág. 5: «Un año después» (editorial).

72 Entrevista del autor con Jaime Arias. Barcelona, 11-II-2004.

73 El País, 20-XI-1976, pág. 6: «Un año después» (editorial). 
sólo las crónicas de dos diarios, El País ${ }^{74}$ y Diario de Navarra ${ }^{75}$, mencionaron este incipiente enfado de los nostálgicos con un Rey que cada vez aparecía más nítidamente como protagonista esencial de la democratización. El resto de periódicos, con intención de eludir todo aquello que supusiese la más mínima erosión de la Monarquía, no hablaron de las voces adversas a los Reyes. En esta línea destacó como protector de la Corona $A B C$; este diario fue el único que afirmó en su crónica sobre el acto de la Plaza de Oriente que se exclamaron vivas al Rey, lo que, en cierta manera, suponía ligarle con el recuerdo del franquismo ${ }^{76}$.

Los gritos contra los Reyes de algunos sectores radicalizados no fueron óbice, al parecer, para que aquellas personas que votaron «no» en el referéndum de la Ley para la Reforma Política, es decir, aquellos identificados con una postura menos favorable al cambio político, no se mostraran especialmente críticos con los Monarcas. Así se desprendía de una encuesta postreferéndum, de comienzos de 1977, donde tan sólo el 1\% de los votantes del «no» cargaron sobre los hombros del Rey los errores de la evolución política obrada tras la muerte de Franco. La misma encuesta puso de manifiesto que un $81 \%$ de aquellas personas que se definían como favorables a la continuidad del Régimen juzgaron positivamente la actuación del Monarca. Éstos son datos dignos de ser tenidos en cuenta pues señalan que, pese a algunos sectores ultras vociferantes y pese a los cambios en sentido democratizador, los leales a la memoria de Franco transfirieron su lealtad al Rey instaurado por su Caudillo ${ }^{77}$. Evidentemente, esto indica también que Juan Carlos I debía considerar prioritaria la consecución de la lealtad de aquellos sectores más alejados del franquismo, y en ello iba a jugar un importante papel su vinculación con la nueva democracia.

Un año después, el 20 de noviembre de 1977, se celebró el segundo aniversario de la muerte de Franco, y la prensa se hizo eco nuevamente de tal conmemoración. Varios diarios publicaron artículos al respecto y en ellos aparecieron menciones al Rey. Buena parte de estas alusiones tuvieron un denominador común: se ensalzaba el papel democratizador de Don Juan Carlos desde su proclamación como Rey hasta ese día, en el que ya se podía afirmar que España gozaba de un sistema democrático, pues se habían celebrado elecciones legislativas en junio. $A B C$ publicó un extenso editorial en su famosa página tres de huecograbado en el que el Régimen franquista recibía una de cal y otra de arena; se alababan sus logros y aciertos, pero también se criticaban sus errores. En clara evolución con respecto a su actitud del año anterior, el veterano diario madrileño consideró

74 Cfr. El País, 21-XI-1976, pág. 1: «Unas 100.000 personas añoraron a Franco en la plaza de Oriente» (crónica sin firma); El País, 21-XI-1976, contraportada: «Ataques al Gobierno y a las instituciones» (crónica sin firma).

75 Cfr. Diario de Navarra, 21-XI-1976, pág. 4: «100.000 personas se concentraron en la Plaza de Oriente» (crónica de Susana Olmo, Pilar Cernuda y Mariano Guindal); Diario de Navarra, 21-XI-1976, pág. 5: «La decadencia del franquismo» (crónica de Amalia Sánchez Sampedro).

76 Cfr. $A B C, 21-\mathrm{XI}-1976$, pág. 9: «Plaza de Oriente: impresionante silencio» (crónica sin firma).

77 Cfr. LINZ, J. J. (dir.): Informe sociológico sobre el cambio político en España 1975-1981. IV Informe FOESSA. Madrid, Euramérica, 1981, págs. 121 y 147. 
que uno de los desaciertos del franquismo fue su concepción de la Monarquía, ya que Franco la contempló «como una especie de prolongación personal y del fantasmal Movimiento, que al fin del régimen ya no significaba nada más que sobrevivir unas semanas ${ }^{78}$. Cebrián Boné, quien fue director de $A B C$, interpreta este giro en la valoración que hizo del franquismo de la siguiente manera:

Hay que contar con que $\mathrm{ABC}$ es un periódico que defendió siempre el 18 de julio. $A B C$, durante toda la etapa del franquismo, pese a su tendencia monárquica y a sufrir correcciones por esto, se mantuvo fiel al 18 de julio. La valoración del franquismo en el editorial del 20-N de 1976, más que una valoración positiva fue un intento por reflejar que había una serie de gente que seguía apoyando a Franco, y se hizo intentando decir que aquello no estaba mal. [...] Destacamos que Franco había hecho posible que viniera la Monarquía, pero sin mucho énfasis. La evolución que se produjo y que se plasmó en el 20-N de 1977 respondía a que ya se habían producido una serie de factores como las elecciones y la nueva estructura de las Cortes. [...] ABC, no con un realismo frío y pragmático, sino con una evolución muy homogénea, reflejó lo que la sociedad estaba viviendo en aquellos momentos ${ }^{79}$.

Del papel del Rey en el tránsito hacia la democracia habló el director de Pueblo en un artículo que mostraba las luces y las sombras del Régimen de Franco. La figura de Juan Carlos I fue destacada por su protagonismo en el proceso de cambio: «Desde el régimen se cambió al régimen, sin que faltaran ni el ímpetu del joven monarca ni el propósito de su Gobierno, ni las manifestaciones del pueblo, ni las incitaciones de la Prensa»80. La misma idea latía, si bien de forma más desarrollada, en un editorial del diario $Y a$, que no hizo referencia al pasado franquista, sino a los dos años transcurridos desde la muerte del Caudillo:

Es justicia estricta destacar como artífice principal de la transición al Rey, cuya dimensión política no ha hecho sino crecer durante este tiempo. No es sólo que don Juan Carlos haya hecho posible la democracia, sino que, en este momento, democracia y monarquía pueden considerarse prácticamente inseparables, y sería una grave irresponsabilidad histórica, si se quiere de veras la primera, prescindir de la segunda ${ }^{81}$.

El prominente quehacer de Juan Carlos I durante la transición fue puesto asimismo de relieve por La Vanguardia, en un editorial en el que el diario catalán tampoco ahorró elogios para el Rey y en el que el franquismo no salía muy bien parado:

En dos años hemos avanzado mucho en los terrenos de la reconciliación nacional, la normalización democrática y la equiparación institucional con los países de nuestro entorno geográfico. Guiados por la firme mano del Rey —motor del cambio-

$78 A B C, 20-\mathrm{XI}-1977$, pág. 3 de huecograbado: «Dos años que parecen siglos» (editorial).

79 Entrevista del autor con José Luis Cebrián Boné. Madrid, 29-X-2003.

80 Pueblo, 21-XI-1977, pág. 3: «Dos años, dos épocas» (artículo de opinión de José Ramón Alonso).

81 Ya, 20-XI-1977, pág. 7: «Dos años de democracia» (editorial). Este artículo de Ya constituyó una especie de advertencia para mantener la Monarquía como forma política de España. No se olvide que la ponencia constitucional llevaba desde finales de agosto trabajando en el borrador de una Constitución que debía definir el tipo de Jefatura del Estado. 
los españoles nos acercamos a cotas de apaciguamiento político interior, para no hablar de respeto exterior, inimaginables hace dos años. Mucho queda, es cierto, por afianzar aún, pero podemos ya comprobar lo que la Monarquía ha supuesto para un país que había quedado anclado en unos modelos y modales políticos y de gobierno que le venían estrechos a su florecimiento y desplazamiento socioeconómico: ha supuesto la recuperación de un calado histórico perdido en los siglos ${ }^{82}$.

En cierto modo, también era el reconocimiento del papel jugado por el Monarca el que hizo a Mundo Diario afirmar, tras una dura crítica al Régimen de Franco, lo siguiente: «El sentido de la grave responsabilidad histórica de un joven Rey permite que la empresa colectiva de edificar una sociedad digna sea ahora posible»83.

Puede afirmarse que la mayoría de los diarios compartieron un discurso básicamente común a la hora de referirse al Rey con motivo del segundo aniversario de la muerte de Franco: marcaron distancias entre uno y otro, y opusieron al Régimen franquista la figura democratizadora de Don Juan Carlos.

La única cabecera disidente de esta opinión fue El Alcázar. El vespertino madrileño - convertido aquellos días en una continua alabanza a su Caudillo y en un instrumento de propaganda para publicitar la manifestación del 20-N en la Plaza de Oriente- ofreció una selección de extractos de discursos y declaraciones de Franco entre los que destacaban los agrupados bajo la denominación «Sobre la Monarquía»84. Estas palabras pronunciadas o firmadas por Franco en su día apuntaban a mostrar las características que debería tener la Monarquía por él instaurada; como puede suponerse, dichas peculiaridades no se correspondían en absoluto con el giro democrático que Don Juan Carlos había impreso a la Corona por él representada. Por tanto, El Alcázar buscó decir de forma indirecta que Don Juan Carlos no había sido fiel al concepto de Monarquía pretendido por la persona que, al fin y al cabo, le había designado Rey. Por otro lado, aunque con la misma intención, el diario ultraderechista fue el único que recogió unas palabras de Blas Piñar en la manifestación de la Plaza de Oriente que parecían apuntar directamente al Rey. Para el líder de Fuerza Nueva, la manifestación que estaba teniendo lugar podía considerarse como un acto de desagravio «frente a desertores que revoloteaban antes con uniforme, en los balcones de este mismo palacio»85. El Alcázar no recogió, sin embargo, los gritos contra el Rey que corearon los manifestantes, como sí lo hicieron las crónicas de Diario 16 y Diario de Navarra: «Dios, Patria, fuera el Rey, viva Cristo Rey» ${ }^{86}$.

82 La Vanguardia, 20-XI-1977, pág. 7: «Dos años después» (editorial).

83 Mundo Diario, 20-XI-1977, pág. 3: «Vencer el pasado» (editorial).

84 El Alcázar, 19-XI-1977, pág. 12. Algunos de los títulos de estos escritos pueden servir para ilustrar su contenido: «Monarquía distinta a la que cayó el 14 de abril»; «Los dos grandes e inolvidables escarmientos: Las Repúblicas anárquicas y las Monarquías liberales y parlamentarias»; «Instauración y no restauración»; «El Estado español, constituido en Reino, nace históricamente del 18 de julio».

85 El Alcázar, 21-XI-1977, pág. 7: «Una jornada memorable» (crónica sin firma).

86 Diario 16, 21-XI-1977, pág. 2: «Plaza de Oriente: los franquistas contra el Gobierno y el Parlamento» (crónica sin firma); Diario de Navarra, 22-XI-1977, pág. 6: «El 20-N transcurrió sin incidentes» (crónica de Colpisa). 
El vocerío contra el Rey se repitió un año después, en la celebración del 20-N de 1978. Los manifestantes corearon: «Que se quede en México, en México, en México; que se quede en México y que no vuelva más" ${ }^{87}$. Fueron varios los diarios que en sus artículos sobre los actos conmemorativos de la muerte de Franco incluyeron estos gritos ultraderechistas contra el Rey, que en aquellos momentos se encontraba de viaje por Hispanoamérica, donde hizo una continua defensa de la democracia como sistema político ${ }^{88}$. Así lo hicieron las crónicas publicadas por Diario 16, La Vanguardia, Mundo Diario, Avui, El Correo y Diario de Navarra ${ }^{89}$. Es llamativo cómo algunos de los periódicos más conservadores omitieron en sus crónicas y comentarios las imprecaciones de los manifestantes contra el Monarca buscando, con toda seguridad, la protección de su figura por la vía de suprimir todo aquello que pudiera erosionarla. Pese a destacar en sus páginas las iras de los nostálgicos del franquismo, los diarios nacidos al calor de la transición $-\mathrm{y}$ situados ideológicamente más a la izquierda - también buscaron defender la figura del Rey de estos enfados, pero lo hicieron mediante la publicación de artículos con este fin. El País pidió mano dura y autoridad firme «contra esa ultraderecha montaraz y golpista» que insultaba «al Rey en calles y plazas " ${ }^{90}$. Más extenso y profundo fue el comentario editorial de Diario 16, que unió los gritos con los gestos reconciliadores que el Rey estaba teniendo en México durante su viaje:

En México, en medio de un eco popular que las cámaras no necesitaban subrayar, los Reyes protagonizaban una emocionante ceremonia de reconciliación de España con su propia historia. Los gritos ultras dirigidos al Rey: ‘¡Que se quede!', adquirieron así su verdadero significado oculto: la petición de que se quede fuera nuestra libertad, nuestro futuro y nuestra identidad ${ }^{91}$.

Miguel Ángel Aguilar, director en aquel momento de Diario 16, afirma que con comentarios como el anterior «se intentaba desvincular al Rey del franquismo porque poníamos el acento en la democratización, pese a que pudiera erosionar de alguna forma su autoridad, especialmente de cara a los militares ${ }^{92}$. Por su parte, Augusto Delkader, entonces subdirector de El País, también asegura que su diario pretendía desligar al Monarca del franquismo, teniendo presente que la fortaleza de

87 Tomado de Diario 16, 20-XI-1978, pág. 5.

88 Los Reyes visitaron México, Perú y Argentina. El análisis del tratamiento periodístico otorgado a la estancia en México está en ZugASTI, R.: «La prensa española ante el viaje del Rey Juan Carlos I a México en noviembre de 1978", en Navajas ZubeldiA, C.: Actas del IV Simposio de Historia Actual. Logroño, Gobierno de La Rioja, 2004, págs. 767-779.

${ }_{89}$ Cfr. Diario 16, 20-XI-1978, pág. 5: «Gritos contra el Rey e insultos contra Gutiérrez Mellado» (crónica sin firma); La Vanguardia, 21-XI-1978, pág. 14: «El mal trago del Gobierno» (crónica de Amalia Sánchez Sampedro); Mundo Diario, 21-XI-1978, pág. 4: «El 20-N se volvió contra el Rey» (crónica de Carlos Santos); Avui, 21-XI-1978, pág. 13: “Cent cinquanta mil veus contra la democràcia» (crónica sin firma); El Correo Español, 21-XI-1978, pág. 25: «Todo son preocupaciones» (crónica de José Cavero); Diario de Navarra, 21-XI-1978, pág. 1: «Manifestación franquista en Madrid» (crónica de Colpisa). Obsérvese cómo incluso Diario 16 y Mundo Diario destacaron en titulares el ambiente hostil al Rey.

90 El País, 21-XI-1978, pág. 8: «Autoridad en defensa de la libertad» (editorial).

91 Diario 16, 23-XI-1978, pág. 4: «Hacer historia» (editorial).

92 Entrevista del autor con Miguel Ángel Aguilar. Madrid, 30-X-2003. 
la Corona no se podía basar en esta unión con el pasado: «Se trataba de que el Rey lo que tenía que hacer era establecer las libertades; en la medida en que hiciera eso, la Monarquía se consolidaría» ${ }^{93}$.

El mismo saldo favorable hacia el Soberano se desprendía de un artículo de Gómez Mompart en Mundo Diario. Tras decir que «los leales, los inquebrantables, los fachas de siempre» renegaban de la Monarquía, afirmó tajante: «Casi todos los balances de los tres años de reinado de Juan Carlos, lógicamente, son favorables" ${ }^{94}$. Por último, un columnista de Deia hizo referencia a las imprecaciones de los nostálgicos y concluyó de la siguiente manera: «Lo cierto es que el único que no va a volver es el dictador ${ }^{95}$.

En la evolución de algunas cabeceras de prensa que, como hemos visto, pasaron de ser condescendientes con el franquismo a enjuiciar muy negativamente algunos de sus aspectos en contraste con la actuación de Juan Carlos I, influyó la percepción mayoritaria que sobre Franco se iba asentando en la opinión pública española.

A este respecto, una encuesta realizada entre mediados de abril y mediados de junio de 1979, pero que preguntaba acerca de 1978, confirmó que el porcentaje de españoles que aprobó totalmente la actuación del anterior Jefe del Estado era tan sólo de un $10,3 \%$ frente a un $32,3 \%$ que la desaprobó totalmente. Por otro lado, un $19,5 \%$ de los encuestados juzgó que, en conjunto, Franco había actuado bastante bien, mientras que un $26 \%$ afirmó que había cometido bastantes errores evitables. Si sumamos los porcentajes, obtenemos que, frente a un $29,8 \%$ de españoles que aceptaron la actuación de Franco, resaltaba la mayoría de un $58,3 \%$ que la reprobaron. Sin embargo, se mantenía un fenómeno al que ya nos hemos referido anteriormente: buena parte de los franquistas habían mantenido su traspaso de lealtad del Caudillo al Rey. Así, al final de la transición tan sólo un 1,5\% de los que aprobaron la actuación de Franco interpretaron que el Monarca había actuado mal hasta la fecha ${ }^{96}$.

\section{CONCLUSIONES}

Tras la muerte de Franco y durante los primeros días de reinado, la prensa destacó mayoritariamente la ligazón del nuevo Rey con el anterior Jefe del Estado y con la legitimidad franquista de la Monarquía instaurada. Esta identificación se diluyó rápidamente en las páginas de los diarios — con la excepción del fiel franquista El Alcázar, que la mantuvo-, más preocupados por destacar todo aquello que dotase a Don Juan Carlos de legitimidad democrática. No sólo ocurrió eso, sino

93 Entrevista del autor con Augusto Delkader. Madrid, 12-V-2004.

94 Mundo Diario, 25-XI-1978, pág. 4: «Y al tercer año, sigue el Rey» (columna de Gómez Mompart).

95 Deia, 23-XI-1978, pág. 17: «TVE: migajas para los vascos» (columna de Kepa Bordegaray).

96 Cfr. LiNZ, J. J., (dir.), op.. cit., pág. 617. 
que la prensa terminó marcando distancias entre Franco y su sucesor conforme el propio Rey actuaba más decididamente hacia el establecimiento de un sistema democrático y a medida que la percepción social del franquismo iba siendo más negativa. Los pasos del Soberano hacia la democracia y la consecución de ésta hicieron que se incidiera cada vez más en la representación de Juan Carlos I como un actor democratizador.

Lo que se buscaba era que el Monarca, empleando el cúmulo de poder que había recibido de la legislación franquista, condujera el cambio de régimen político. Éste era el objetivo de la prensa en su conjunto, compartido con el Rey, sobre el que se cimentó pragmáticamente una relación de complicidad entre los actores periodísticos y la Corona. De ahí que la prensa optara por no recordar - salvo lógicamente con motivo de la proclamación- el origen y la legitimidad franquista de la Monarquía, ya que ésta podía erosionar la figura de Don Juan Carlos de cara a conseguir la adhesión de los sectores contrarios al franquismo. Pese a lo anterior, ni el Régimen del 18 de julio ni la contienda que le dio su legitimidad de poder fueron temas tabú para la prensa. Los periódicos hablaron de este pasado reciente de acuerdo con sus principios y sus estrategias políticas, pero no lo utilizaron como arma arrojadiza contra la Monarquía, sino para fortalecerla.

Podemos concluir asimismo que la prensa en su conjunto apoyó el tránsito a una democracia que fuera aceptada por todos, pues ha quedado demostrado cómo en el caso estudiado reforzó la imagen del Rey en sentido liberalizador, precisamente para contribuir a que el Monarca tuviese la solidez suficiente que le permitiera seguir el rumbo hacia la democracia. La prensa se convirtió también, por consiguiente, en un actor colectivo de la esfera pública que, pese a las lógicas diferencias entre cabeceras, contribuyó positivamente al establecimiento pacífico de un sistema democrático en España. Compartió así tarea y responsabilidades con aquellos actores que, cada uno desde su posición y con sus propias armas, actuaron en la misma dirección: el propio Rey, otros gobernantes, la oposición democrática y sindical, sectores mayoritarios del Ejército, la Iglesia o el pueblo español en su acepción más amplia.

Durante el periodo en que institucionalmente se completó la transición, la periódicos forjaron la imagen de Juan Carlos I que se ha mantenido hasta nuestros días, caracterizada fundamentalmente por el énfasis puesto en su papel como actor democratizador. Por lo tanto, cabe concluir que, por lo que respecta a la prensa, no se ha producido únicamente una legitimación democrática de la Monarquía a posteriori, sino que a finales de 1978 el Rey aparecía ya ante los ojos de la opinión pública revestido totalmente de la legitimidad democrática que había ido consiguiendo con su actuación y que la prensa había ido ensalzando y difundiendo como parte esencial de su complicidad con la Corona. 